\title{
REVIEW
}

\section{VACCINES IN PREGNANCY: A REVIEW OF THEIR IMPORTANCE IN BRAZIL}

\author{
Lucia Ferro Bricks
}

BRICKS LF - Vaccines in pregnancy: a review of their importance in Brazil. Rev. Hosp. Clín. Fac. Med. S. Paulo 58 (5):263$274,2003$.

Neonates and young children remain susceptible to many serious infectious diseases preventable through vaccination. In general, current vaccines strategies to prevent infectious diseases are unable to induce protective levels of antibodies in the first 6 months of life. Women vaccinated during pregnancy are capable of producing immunoglobulin antibodies that are transported actively to the fetus, and maternal immunization can benefit both the mother and the child. With few exceptions, maternal immunization is not a routine, because of the concerns related to the safety of this intervention. Ethical and cultural issues make the studies on maternal immunization difficult; however, in the last decade, the development of new vaccines, which are very immunogenic and safe has reactivated the discussions on maternal immunization.

In this paper we present a review of the literature about maternal immunization based on MEDLINE data (1990 to 2002).

The most important conclusions are: 1) there is no evidence of risk to the fetus by immunizing pregnant women with toxoids, polysaccharide, polysaccharide conjugated and inactive viral vaccines; 2) most viral attenuated vaccines are probably safe too, but data is still insufficient to demonstrate their safety; therefore these vaccines should be avoided in pregnant women; 3) in Brazil, there is a need for a maternal immunization program against tetanus.

Many new candidate vaccines for maternal immunization are available, but studies should be conducted to evaluate their safety and efficacy, as well as regional priorities based on epidemiological data.

DESCRIPTORS: Vaccines. Pregnancy. Maternal immunization. Infectious diseases. Neonatal.

Immunization is considered one of the most important measures to control infectious diseases and the recommendations for routine immunization are based on the analysis of risks, benefits and cost of immunobiologicals ${ }^{1,2}$. Despite the huge impact of immunization programs on the reduction of morbidity and mortality associated with vaccine preventable diseases, newborns and breast-feeding babies remain vulnerable to several diseases caused by viruses and bacteria ${ }^{1-24}$.

The immune system of breast-feeding babies is not mature enough to respond to some types of immunobio- logicals and, even when vaccines are administered in the first few months of life, a latency period is required to obtain antibody titers in sufficient amounts to confer protection on the child. Another concern is the possibility that the antibodies acquired passively from the mother could affect the response to vaccines containing live attenuated viruses ${ }^{3-10}$.

From the Children's Institute, Hospital das Clínicas, Faculty of Medicine, University of São Paulo - São Paulo/SP, Brazil. Received for publication on April 08, 2003.
Pregnancy offers an excellent opportunity to increment mothers' and babies' immunity. Pregnant women are capable of producing suitable amounts of antibodies and the transfer of such antibodies to the fetus through the placenta occurs during the last 4 to 6 weeks of pregnancy ${ }^{9}$. Most IgG class antibodies are capable of crossing the placenta barrier. The concentration of subclass IgG1 antibodies can be higher in the cord blood than in maternal blood, thus suggesting that there is an active transfer of antibodies in the placenta ${ }^{9}$. The antibodies acquired passively by the child can confer protec- 
tion on the newborn against a variety of serious disease ${ }^{3-10}$.

Until the 1960's, knowledge about the possible deleterious effects of the products administered to pregnant women on fetuses was very limited, and many vaccines were administered to pregnant women. In the United States, from 1957 to 1966 vaccines against influenza and poliomyelitis were routinely administered in maternal immunization programs. Results from a major seven-year study nationwide (Collaborative Perinatal Project) involving more than 50,000 pregnant women and their children, where occurrences such as malformations, learning disorders, hearing deficiency and risk of neoplasias were investigated, demonstrated that the vaccines against poliomyelitis (oral and inactivated), influenza, diphtheria, tetanus and smallpox did not have adverse consequences for mother or fetus ${ }^{7,9}$.

After verifying the deleterious effects of thalidomide on babies from pregnant women who had taken that drug, a deep concern was aroused over the safety of pharmaceutical drug use (including vaccines and immunoglobulins) during pregnancy. Despite no evidence of risk of malformation being associated with vaccines, there is great fear that immunobiologicals can cause some type of harmful effect on the fetus. Therefore, whenever possible, vaccines recommended for pregnant women should be administered in the latter stages of pregnancy, when the fetus has already formed. This step seeks to prevent that any malformations and abortions that may occur, irrespective of vaccination, be ascribed to the vaccines ${ }^{3-10}$.

The difficulties in conducting studies in pregnant women limit the evaluation of the results due to the small number of cases. However, many women of childbearing potential were vaccinated before knowing they were pregnant, and the follow-up of these women and their children has produced important information on vaccine safety both for mother and baby. In addition, in the past decade the development of increasingly safer and more immunogenic vaccines against several infectious agents that cause serious diseases in breast-feeding babies has reawakened discussions about the risks and benefits of vaccinating pregnant women, particularly where there is a high risk that the pregnant woman and/or fetus develop infection with serious consequences ${ }^{3-10}$.

In this study we present revised data from the literature about the indications and contraindications of the use of vaccine and immunoglobulins by pregnant women, through the surveying of publications on the subject issued over the past 10 years.

\section{Considerations of the advantages and disadvantages of maternal immunization}

Newborns belong to a group which is highly vulnerable to several viral and bacterial infections ${ }^{1,11-18}$. Since, for the most part, vaccines are recommended for breast-feeding infants on three-dose schemes, at 2, 4 and 6 months, before the sixth month of life children are unprotected, or only partially protected against vaccine preventable diseases ${ }^{1,3-10}$. The vaccination of pregnant women could overcome this difficulty, conferring passive protection on the baby and affording a valuable opportunity to provide mother and child with immunity. The best example of the efficacy of this measure is the disappearance of neonatal tetanus in developed countries, where routine vaccination of pregnant women against tetanus has been a common practice for several decades ${ }^{3-10}$.

In industrialized countries, group B Streptococcus and gram-negative enterobacteria are the main bacterial agents for serious neonatal infections ${ }^{14,20,21}$.
Except for the neonatal period, during the first 6 months of life the Streptococcus pneumoniae is the main bacterial agent for pneumonias and bacteremias in most countries ${ }^{1,14}$. Although the S. pneumoniae rarely causes sepsis in the neonatal period, 171 cases of neonatal sepsis by that bacterium were identified in the USA; in cases of early development sepsis ( $<48$ hours) the prognostic and death rate were higher than in cases of late development sepsis ${ }^{20}$.

Whereas infections by Haemophilus influenzae type b have virtually disappeared in developed countries, in developing countries that bacterium is still responsible for a large number of pneumonia, meningitis, bacteremia and sepsis cases in children under 5 , particularly in non breast-feeding infants ${ }^{1,14}$.

The prevalence of infections caused by Neisseria meningitidis varies largely, being higher in populations living in poor conditions; nevertheless, even in developed countries these infections present high rates of morbidity and mortality in breast-feeding babies ${ }^{14,22,23}$.

Among viral infections are to be included those caused by the respiratory syncytial virus and rotavirus, respectively the most important agents for respiratory disease and gastroenteritis in breast-feeding babies. The viruses of influenza, parainfluenza, herpes simplex, cytomegalovirus and enterovirus are also an important cause of morbidity among breast-feeding babies $^{15-19}$.

The objective of maternal immunization is to afford newborns and breast-feeding babies sufficient quantities of specific antibodies against the pathogens that cause serious infections during this highly vulnerable pe$\operatorname{riod}^{2-10}$.

During pregnancy, women are capable of producing sufficient quantities of antibodies. Although class $\operatorname{IgM}, \operatorname{Ig} \mathrm{A}$, 
$\operatorname{IgD}$ and $\operatorname{IgE}$ antibodies do not cross the placenta, class $\operatorname{IgG}$ antibodies can be actively transferred to the fetus through the placenta. The half-life of maternal antibodies is 3 to 4 weeks and the persistence of these antibodies depends on the initial titers. Typically, after 6 months of age, maternal antibodies have already disappeared or are present in low titers; however, during the second semester of life, children who have been suitably immunized already present their own antibodies against vaccine antigens. Women vaccinated during pregnancy can also transfer specific antibodies against several pathogenic agents through the colostrum and maternal milk and, in this case, there is also a transfer of $\operatorname{IgA}$ class antibodies in addition to that of $\mathrm{IgG}^{9}$.

The main difficulties in implementing vaccination programs for pregnant women as a public health intervention relate to the theoretical considerations over the potential risks of vaccines for pregnant women and fetus, the relatively limited knowledge in that field and the technical, ethical as well as legal difficulties in conducting studies on the risks and benefits of vaccination for pregnant women ${ }^{2-10}$.

The potential risks of maternal immunization are, generally speaking, the same as those for the population, and are directly related to the specific product. However, during this period there is a concern that the occurrence of adverse events could have implications on the course of the pregnancy or induce premature labor. The experience with the vaccines habitually recommended for maternal immunization offers no backup for this concern; still, it is recommended that vaccination during the first trimester of pregnancy be avoided ${ }^{1-10}$.

The main disadvantages of maternal immunization include absence of the benefits of this measure when there is premature birth, the potential risk that the mother's antibodies would af- fect the immunological response of the newborn, whether by inducing immunological tolerance or by inactivating certain vaccines containing live attenuated viruses. In the first situation, one should consider that the production of maternal antibodies after vaccination is not immediate and that the transfer of maternal antibodies to the fetus only occurs in the last 4 to 6 weeks of pregnancy ${ }^{8,9}$.

\section{Situation of vaccine preventable diseases in Brazil}

Over the past 20 years there has been a sharp reduction in the number of cases of some vaccine preventable diseases in Brazil, mainly due to increased vaccine coverage and to the introduction of mass vaccination campaigns. While some diseases were gradually disappearing, others were recognized as being important for public health (Table 1).

The best example of the impact that vaccination had on disease reduction is poliomyelitis, which was eliminated from this country after the introduction of mass vaccination campaigns in the 1980's. The last case of paralytic polio in Brazil was registered in 1989. An inverse example is tuberculosis, which persists as a major public health issue despite the excellent vaccine coverage. The tuberculosis vaccine is quite effective in the prevention of serious forms of the disease, e.g. tuberculous meningitis; however, to control this disease other measures are necessary besides vaccination.

Despite the substantial reduction in cases of diphtheria, tetanus and whooping cough in the year 2001, 19 cases of diphtheria (3 deaths), 1,464 cases of whooping cough (13 deaths), 366 cases of accidental tetanus (86 deaths) and 34 cases of neonatal tetanus (27 deaths) were registered. The death rates for these diseases are considerably high, reaching $79 \%$ in cases of neonatal tetanus ${ }^{23}$.

In 1997 there was a measles epidemic in Brazil, with 53,664 cases and 61 deaths.

After a national vaccination campaign against measles and reinforced actions for epidemic surveillance, circulation of the measles virus in Brazil was finally interrupted, with only 1 case being diagnosed in 2001 and another in 2002, both imported from Japan. With regard to rubella, up until the mid-nineties information on its in-

Table 1 - Number of notified cases of some vaccine preventable diseases in Brazil, in 1982 and 2000, according to the Ministry of Health.

\begin{tabular}{lll}
\hline Compulsory notification diseases & 1982 & 2000 \\
\hline Hepatitis B & $?$ & 6,396 \\
Tuberculosis & 87,822 & 93,360 \\
Diphtheria & 3,297 & 58 \\
Accidental Tetanus & 2,226 & 525 \\
Neonatal Tetanus & 584 & 41 \\
Whooping Cough & 54,766 & 2,464 \\
Haemophilus influenzae type b meningitis & $?$ & 577 \\
Measles & 39,370 & 36 \\
Rubella & $?$ & 14,767 \\
Congenital Rubella Syndrome & $?$ & 79 \\
Yellow Fever & 24 & 85 \\
Meningococcal Disease & 1,226 & 4,592 \\
Human Rabies & 127 & 26 \\
Hepatitis A & $?$ & 20,310 \\
\hline
\end{tabular}

Source: Ministry of Health/FUNASA/CENEPI 
cidence in this country was virtually nil; in 1997, when notification became compulsory, 32,825 cases of rubella and only 17 cases of congenital rubella syndrome (CRS) were confirmed. Considering the difficulty in confirming CRS diagnosis, one can argue that this information surely underestimates its importance. In 1999 and 2000 an epidemic of rubella broke out, with a high percentage of the cases being diagnosed in women in fertile age and so a national vaccination campaign was launched against rubella for this group. The number of CRS cases in 1999, 2000 and 2001 was 39, 79 and 39 respectively. Probably, these numbers underestimate the real importance of rubella in Brazil because of the many difficulties involved in making a diagnosis of CRS. There is no national record for the number of mumps and chickenpox cases and we should note that case notification for many diseases do not reflect their actual incidence, due to the large number of oligosymptomatic or asymptomatic cases and to the difficulties in establishing etiological diagnosis ${ }^{22,23}$.

Information on meningitis caused by Haemophilus influenzae was scarce until the early 1990's; the largest number of Hib meningitis cases in Brazil $(1,684)$ was registered in 1995 . The vaccine against Hib was introduced into the national immunization calendar in the latter part of 1999, inicially only for children less then 24 month; during that year the number of Hib meningitis cases was 1,368 , dropping to 577 in 2001 and to 234 in 2001.

In the year 2000, respiratory diseases were the second cause of hospitalization in Brazil (16.2\%). Although the main causes of hospitalization for respiratory disease are ascribed to pneumonia, caused by $S$. pneumoniae, $H$. influenzae, influenza virus and Respiratory Syncytial Virus, we do not have information available on the incidence of these infections.

\section{Vaccines routinely recommended for pregnant women}

Vaccines recommended for pregnant women should be little reactogenic, safe for mother and fetus and capable of inducing a good response of class IgG1 antibodies. Ideally, vaccine components should be specific, highly purified and a single dose should be sufficient to obtain high antibody titers. In order to obtain a suitable transfer of antibodies to the fetus, the minimum interval between vaccine administration and childbirth should be two weeks ${ }^{1-10}$.

Although several vaccines have been investigated for use in pregnant women, currently few vaccines are routinely recommended, as shown in table $2^{1}$.

\section{Vaccines against diphtheria and tetanus $^{1,2}$}

The best example of the effectiveness of vaccinating pregnant women is the reduced number of cases of neonatal tetanus in the past decade. In 1989, the World Health Organization set out to eliminate neonatal tetanus between 1995 and 2000. With an increase in vaccine coverage a substantial reduction in cases of neonatal tetanus was actually observed. However, over 400,000 cases of neonatal tetanus are estimated to occur worldwide, most occuring in developing countries, where vaccine coverage is poor and neonatal tetanus accounts for 23 to $73 \%$ of deaths during the neonatal $\operatorname{period}^{27}$.

Tetanus and diphtheria toxoids are undoubtedly safe, immunogenic and capable of stimulating the production of significant amounts of antibodies in pregnant women, inducing protection for both mother and baby ${ }^{1-10,25-27}$.

In Brazil, 296 cases of neonatal tetanus were notified in 1990 and the number of cases dropped to 41 and 34 in 2000 and 2001, respectively ${ }^{23}$. Most cases of neonatal tetanus result from failure to vaccinate, as 2 doses of antitetanus vaccine administered no later than 6 weeks before childbirth protect both mother and fetus, even if the pregnant woman has not received a previous dose of the vaccine ${ }^{1,22,23,27}$.

Table 2 - Vaccination of pregnant women.

\begin{tabular}{|c|c|c|c|}
\hline $\begin{array}{l}\text { Routinely Recommended } \\
\text { Vaccines }\end{array}$ & $\begin{array}{l}\text { Vaccines to be indicated only in } \\
\text { special situations }\end{array}$ & Vaccines under investigation & Contra-indicated vaccines \\
\hline Adult combined (dT) & Against poliomyelitis (oral or inactivated) & Pneumo conjugate & Measles \\
\hline Tetanus and diphtheria toxoids & Pneumococcal polysaccharide (Pn23-valent) & Meningo conjugate & Mumps \\
\hline \multirow[t]{6}{*}{ Influenza } & Menigococcal polysaccharide & Acellular pertussis & Rubella \\
\hline & Yellow fever & Group B streptococcus & Chickenpox \\
\hline & Hepatitis A & Respiratory syncytial virus & $\mathrm{BCG}$ \\
\hline & Hepatitis B & Parainfluenza-3 & \\
\hline & Rabies & Herpes simplex & \\
\hline & Japanese encephalitis & $\begin{array}{l}\text { Attenuated vaccine against } \\
\text { influenza }\end{array}$ & \\
\hline
\end{tabular}


Pregnant women who are not vaccinated, or are only partially vaccinated against tetanus $(<$ three doses $)$ should receive at least 2 doses of the antitetanus vaccine $(\mathrm{T})$ or the adult combined vaccine $(\mathrm{dT})$ at a minimum one-month interval in between, preferably after the first trimester of pregnancy and at least fifteen days prior to childbirth. Pregnant women who have been vaccinated with 3 or more doses of antitetanus vaccine and have received a booster dose within the past 5 years do not need to be vaccinated. For those who have not received a booster dose, or received the last dose more than 5 years ago, administration of 1 dose of antitetanus vaccine (T) or adult combined (dT) is recommended at least 2 weeks prior to childbirth ${ }^{1,22,23}$.

\section{Vaccine against influenza}

Pregnant women and children less than 1 year of age face a high risk of complications associated with the influenza virus. In pregnant women in the third trimester of pregnancy the risk of complications is higher than in young adults who present risk conditions ${ }^{28-35}$

Vaccines against influenza contain dead viruses or subunits, thus being non-infectious. Vaccines containing subunits only are highly purified and little reactogenic, still they are not recommended for children under 6 months due to their low immunogenicity. For the first vaccination children between 6 and 36 months old should receive 2 doses of the vaccine ${ }^{1}$. Thus, in the first year of life, even when vaccinated, children are highly vulnerable to infections by the influenza virus ${ }^{33}$.

Since the late 1970's, it has been demonstrated that babies with high titers of antibodies against the influenza virus in the cord blood have presented low rates of infection during epidemic outbreaks; therefore, vaccination of pregnant women could benefit both mother and child ${ }^{29,30}$. A study conducted in Houston between 1975 and 1977 has shown a positive correlation between titers of neutralizing antibodies in the cord blood and protection against the strain of influenza A/Victoria virus, since none of the children who presented antibody titers above 1:8 in the cord blood against this strain was infected by the influenza virus in the first 8 weeks of life ${ }^{29}$.

Administration of inactivated vaccines against influenza to pregnant women is safe and, in comparison to the population, pregnant women produce similar antibody titers; passive protection conferred on the children of vaccinated pregnant women persists for at least 2 months (half-life from 35 to 50 days) $)^{29-31}$.

In the United States, the vaccine against influenza is recommended for pregnant women expected to be in the second or third trimester of pregnancy when circulation of the influenza virus is at its peak, and for those who present a risk condition, irrespective of the stage of pregnancy ${ }^{33}$. This recommendation is based on information relating to vaccine safety during all stages of pregnancy and on the absence of adverse events for the child ${ }^{28-35}$.

The advantages of vaccinating pregnant women against influenza include mother's protection at a time when the risk of complications is at its highest, reduction in the potential of a mother who, upon contracting the infection, transfers it to her child in the first months of life, and the transfer of antibodies to the fetus, conferring passive protection in the first weeks of life. Although it is difficult to estimate the duration of passive protection, the half-life of antibodies acquired passively is estimated to be of 21 days, yet it is possible that this protection could be extended for much longer ${ }^{25-29}$.

\section{Vaccines recommended for pregnant women in special situations only}

\section{Vaccines against poliomyelitis}

Oral or injectable vaccines against poliomyelitis are highly immunogenic and effective for poliomyelitis prevention. In the fifties, they were largely used by American pregnant women due to the high risk of infection by the wild virus. There was no confirmation of serious adverse events in pregnant women or their babies ${ }^{36,37}$. More recently, due to poliomyelitis outbreaks in Finland, more than 3,000 pregnant women were given the oral vaccine against polio, again demonstrating the safety of such vaccine ${ }^{12}$. In 1988 an epidemic of poliomyelitis caused by poliovirus type 1 broke out in Israel; in October 1988 all individuals less than 40 years old (including pregnant women) received the oral vaccine against poliomyelitis. No adverse effects were reported in vaccinated pregnant women or in their offspring, and an analysis of 88 newborns weighing more than 2,500 $\mathrm{g}$ revealed a transfer of antibodies against poliovirus type 1 and 2; the titers against the poliovirus type 3 were low ${ }^{37}$.

So far there is no evidence that the vaccines (oral or injectable) against poliomyelitis cause unwanted effects for the pregnant woman or the fetus $^{1,9,12}$.

In Brazil, since 1980, mass vaccination campaigns against poliomyelites have led to elimination of the disease in the country. No case of polio has been reported in the past decade. Since the risk of poliomyelitis is currently very low, maternal immunization is not recommended ${ }^{22,23}$.

Only in special circumstances should pregnant women receive oral vaccine against poliomyelitis. For example, non-immune pregnant women who are expected to go to areas where 
the wild virus still causes endemic disease (some African regions and the Southeast of Asia) should be vaccinated against polio $^{1,22,23}$.

\section{Vaccines against hepatitis $B$}

Breast-feeding babies infected by the hepatitis $B$ virus are at a high risk of becoming chronic carriers of the HBs antigen (HBsAg). The vaccine against hepatitis B is highly purified, safe and effective, inducing a high rate of protection among children and adults $(>90 \%)$. Although it is not routinely recommended for maternal immunization, neither pregnant women, inadvertently vaccinated, nor their babies presented adverse effects after administration of the vaccine and/or specific immunoglobulin (HBIG) ${ }^{1,38-40}$.

A study of 37 pregnant women vaccinated against hepatitis B during pregnancy showed that all newborns from mothers who had developed antibody titers against the HBs antigen above 1:35 $\mathrm{mUI} / \mathrm{ml}$ exhibited titers, considered as being protective, in the cord blood (above 1:10 mUI/ml) ${ }^{39}$. In another study, 49\% (39 out of 80) pregnant women vaccinated against hepatitis B presented seroconversion; this percentage is low; however, most of them had received 1 or 2 doses of the vaccine. Obese pregnant women, smokers or over $25 \mathrm{~s}$ presented lower antibody titers than younger, nonobese and non-smoking women ${ }^{40}$.

The doses and scheme recommended for the prophylaxis of pregnant women after exposure to the hepatitis B virus are the same as those recommended for the population ${ }^{1,38-40}$.

In Brazil, up until 1998 the vaccine against hepatitis B was only available for high-risk groups and few women in fertile age were vaccinated ${ }^{22,23}$. Therefore, we consider it essential to conduct specific serology for hepatitis B during the prenatal period, since, if the mother is an HBsAg carrier, the newborn will have to receive immuno- prophylaxis within the first 12 hours of life (vaccine + specific immunoglobulin). If the pregnant woman is HBsAg negative, she will have to be vaccinated during pregnancy only if she belongs to a risk group for hepatitis $\mathrm{B}^{1}$.

Since the risk of contracting the disease is high among adolescents and many pregnant adolescents will go through new pregnancies, it is recommended that pregnant adolescents who are seronegative for hepatitis $\mathrm{B}$ be vaccinated after childbirth. The vaccine against hepatitis $B$ is available for the entire population less than 20 years old 22,23 .

\section{Vaccine against hepatitis $A$}

The vaccines against hepatitis $A$ contain dead viruses and are not infectious; they are highly purified, effective and induce long-lasting protection. It is believed that they are not harmful to pregnant women or the fetus; however, since only recently have they been licensed and are not much used routinely, there is little information regarding their safety for pregnant women. The risk of vertical transmission of hepatitis A is low, therefore the vaccine is not recommended for pregnant women.

In cases where post-exposure prophylaxis is needed, normal human immunoglobulin is recommended within 15 days of exposure, and the same schemes and doses as recommended for the population apply. If the pregnant non-immune woman intends to travel to highly endemic regions for longer than 5 months, the vaccine may be administered concurrently with the immunoglobulin, in separate parts ${ }^{1,9,41}$.

\section{Vaccines against yellow fever}

Yellow fever is a rare disease in industrialized countries ${ }^{42}$; however, in Brazil the wild form is still endemic in several parts of the country ${ }^{22}$. As death rates are very high and no specific treatment is available for this disease, the vaccine against yellow fever has been included in the national vaccination calendar, from 9 months of age, with booster doses every 10 years. This recommendation is valid for nearly the entire national territory (except for a few states in the South and Southeast) ${ }^{22,23}$.

The vaccines against yellow fever contain live attenuated viruses and so they are not routinely recommended for pregnant women, except when they reside in risk areas ${ }^{1,42-44}$.

Many pregnant women unaware of their condition were inadvertently vaccinated against yellow fever, whether in endemic regions or during vaccination campaigns. Luckily, todate, no serious adverse effects have been confirmed in the pregnant women and/or fetuses ${ }^{1,43,44}$.

Although the vaccine is considered safe for both pregnant woman and fetus, whenever possible it is recommended that pregnant women planning a journey to risk areas should postpone their trip. If this is not possible, the vaccine should be administered at least two weeks before the pregnant woman travels to risk $\operatorname{areas}^{1,22,42-44}$.

\section{Polysaccharide vaccine against pneumococcus}

The 23-valent vaccine is recommended only for individuals who face risk (patients with chronic diseases, with anatomic or functional asplenia, old-aged and immunodepressed people) and are over 2 years old. Since this vaccine is highly purified, safe and immunogenic among adults, it can be administered to pregnant women in risk groups. Since a lot of women only have access to health services during the prenatal and delivery period, in such instances it should be checked whether the use of pneumococcal polysaccharide vaccine is indicated ${ }^{1,45-51}$. 
Some authors evaluated the response of pregnant women to polysaccharide vaccines against the pneumococcus and the results from all studies indicated that these vaccines are safe and capable of inducing immunologic response. In addition to protecting pregnant women, they are likely to protect the baby passively through transplacental crossing of antibodies and transfer of antibodies through the colostrum and maternal milk ${ }^{45-51}$.

\section{Polysaccharide vaccines against meningococci}

Polysaccharide vaccines against A, $\mathrm{C}, \mathrm{Y}$ and $\mathrm{W} 135$ groups meningococci are recommended only in risk situations. They are highly purified and immunogenic vaccines, and they offered no risk for vaccinated pregnant women nor did they affect response to vaccination in babies whose mothers had been vaccinated during pregnancy. Although the crossing of antibodies from mother to fetus is variable, in addition to conferring protection on the pregnant woman, the vaccines can afford increased immunity on the newborn $^{1.52-54}$.

\section{New perspectives: vaccines under investigation}

During the neonatal period, the group B streptococcus and enterobacteria account for most bacterial infections and, in the first few months of life, babies are very vulnerable to invasive infections by encapsulated bacteria such as Haemophilus influenzae type b, Streptococcus pneumoniae and N. meningitidis $^{1-10}$. The quest for safe and effective vaccines for these agents has been very successful, particularly with the development of conjugate vaccines against the Hib, pneumococcus and meningococcus, already licensed in several countries ${ }^{55}$.

Despite the success, young breast- feeding babies remain at a high risk of contracting these infections, since multiple doses of conjugate vaccines are required. Vaccination of pregnant women against these agents is considered a valid alternative to offer protection to babies in the first few weeks of life $^{56}$. Although little has been studied about vaccination of pregnant women with new conjugate vaccines against Hib, pneumococcus and meningococcus, results from studies published in the past decade are very promising $^{2-10}$.

\section{Conjugate vaccines against Hib}

Hib invasive diseases usually affect young babies and, since the eighties, the role of polysaccharide vaccines against Hib in pregnant women has been studied, with the purpose of reducing the impact of the disease on breastfeeding infants. Pregnant women respond well to polysaccharide vaccines and studies have shown that they are safe both for pregnant woman and fetus, besides demonstrating that there is a passive transfer of antibodies through the placenta and the maternal milk ${ }^{56-62}$. Conjugate vaccines against Hib are capable of inducing production of class igG1 antibodies in titers higher than those obtained from non-conjugate vaccines. In some studies, antibody titers against the Hib found in the cord blood were higher than maternal titers, suggesting active transfer of such antibodies. We should note that the antibodies transferred through the placenta do not affect immunological response to the vaccine administered after six weeks of life ${ }^{58-62}$.

After conjugate vaccines against the Hib were incorporated into national immunization programs and invasive diseases by this bacterium were virtually eliminated, their indication for pregnant women became very limited. Still, studies involving these vaccines are considered excellent models for the study of other vaccines in pregnant women ${ }^{9,56-62}$.

\section{Conjugate vaccines against $S$. pneumoniae}

S. pneumoniae is the main agent for pneumonia in almost every age group; it is among the 3 main agents causing bacterial meningitis, besides causing several types of infection, e.g. acute otitis media, sinusitis, bacteremia and sepsis, among others ${ }^{1,5,14}$.

Today more than $90 \mathrm{~S}$. pneumoniae serotypes are recognized, however, because cross immunity among different serotypes is low, the prevention of diseases caused by the pneumococcus requires polyvalent vaccines ${ }^{1}$.

Children under two years of age constitute a high-risk group for serious infections caused by the $S$. pneumoniae; however, the 23-valent polysaccharide vaccine is only recommended for high-risk groups over two years old due to its low immunogenicity in breast-feeding infants ${ }^{1}$.

A new conjugate vaccine containing seven pneumococcus serotypes has been licensed recently. It is recommended for breast-feeding infants over six weeks old ${ }^{49}$. Despite being extremely safe, immunogenic and very effective against serious forms of the disease, the 7-valent conjugate vaccine is expensive and its scope of protection is limited to the serotypes contained in the vaccine. Since it is necessary to administer 3 doses of the vaccine, at 2, 4 and 6 months, up until the sixth month of life, children less than six months are only partially protected. A large percentage of the cases of invasive disease caused by pneumococcus occur in breast-feeding infants less than 6 months old, so it is essential to look for new alternatives of prevention for diseases caused by this bacterium. Polysaccharide vaccines against the pneumococcus administered to pregnant women in the third 
trimester of pregnancy are safe for mother and fetus and, theoretically, they could confer some degree of protection on newborns ${ }^{45-47}$.

In comparison to polysaccharide vaccines, conjugate vaccines are more immunogenic and capable of reducing the number of $S$. pneumoniae carriers. It is possible that the vaccination of pregnant women with these new vaccines should afford higher antibody titers in babies, conferring extended protection; however, their scope of protection is limited. As yet we do not know whether the new pneumococcal conjugate vaccines administered to pregnant women and to breast-feeding infants will have an impact on collective immunity. We should remember that the number of $S$. pneumoniae serotypes capable of causing invasive diseases and disease of mucous membranes is much higher than that of $H$. influenzae, which is almost exclusively restricted to the $\mathrm{Hib}^{9,10}$.

\section{Vaccines against group B streptococci}

The group B streptococcus (GBS) is among the most important pathogen in the neonatal period and in children less than three months old ${ }^{1,63-65}$. It is estimated that the incidence of serious diseases caused by the GBS is 3 out of 1,000 living newborns. In the USA alone, every year 11,000 cases of sepsis or meningitis by the GBS are reported. GBS accounts for 2,500 deaths every year and although 1,350 children survive, they are left with serious after effects ${ }^{65}$. Besides attacking young babies, the GBS causes enormous morbidity in pregnant women, and is one of the main agents of urinary infections, chorioamnionitis, endometritis and infections from surgical wounds in the puerperium. Despite recommendations for the use of prophylactic antibiotics in risk groups, the disease still has a high incidence and is very serious ${ }^{63-65}$.
Studies conducted in the 1970's established a relationship between antibody deficiency against the GBS's polysaccharide capsule in pregnant women and the susceptibility of both mother and fetus to infections. In the 1980's, polysaccharide vaccines against the group B streptococcus were tested in pregnant women, with promising results. Although the vaccines containing polysaccharides from the GBS capsule were safe, the immunological response against the different types of GBS varied ${ }^{63-65}$.

Immuno-protective response - defined as reaching antibody titers above $1 \mathrm{mcg} / \mathrm{ml}, 4$ weeks after vaccination was achieved in approximately $40 \%$ of those vaccinated against type Ia, $88 \%$ against type II and $60 \%$ against type III, indicating the need for more immunogenic vaccines ${ }^{63-65}$.

Later on, with the technology of conjugate vaccines, vaccines containing the GBS polysaccharide capsule's, conjugated with tetanus toxoid against several GBS serotypes (Ia Ib, II, III) were developed. These new vaccines are highly immunogenic and safe, both in animals and in adult volunteers, and they should be useful for pregnant women; however, the development of conjugate vaccines against the GBS is hindered by the number of pathogenic serotypes. It is thus necessary to develop multivalent vaccines against several serotypes (Ia Ib, II, III and V).

Conjugate vaccines against serotypes III and V are currently undergoing clinical tests, and their safety and immunogenicity have already been demonstrated in adults, including women of childbearing potential. Conjugate vaccines for use in animal models are currently undergoing tests in order to evaluate fetus protection ${ }^{66}$.

\section{Acellular vaccines against whooping cough}

In developed countries, where vaccines against the whooping cough have been largely used for over 40 years, the disease persists as an important cause of morbidity, especially among young babies. In the United States, Canada and several countries in Europe there has been an increase in the number of whooping cough cases, with a deviation of the age group with the highest incidence of the disease. Today $25 \%$ to $35 \%$ of the cases are diagnosed in adolescents and adults. These individuals are the main reservoirs of the $B$. pertussis and several cases were documented where the mother, grandparents or health care professionals were to account for the transmission of the disease to babies. Most complications, hospitalizations and deaths from whooping cough occur in the first six months of life, a time when the child is still unprotected against the disease, despite vaccination $^{1,67,68}$. In Brazil, all 27 whooping cough deaths registered in the year 2000 occurred in children less than one year old ${ }^{23}$.

Since the forties, the role of antibodies against $B$. pertussis for disease protection has been known and, in the fifties, pregnant women vaccinated against whooping cough were noted to transfer their antibodies to the fetus $^{68}$. Nonetheless, whole cell vaccines against whooping cough are not recommended after 7 years of age due to their reactogenicity ${ }^{1}$. Recent development of acellular vaccines against the whooping cough - already licensed for children and adults - has prompted discussion over their indication for adolescents, adults and perhaps pregnant women, in order to boost protection against this serious disease $\mathrm{e}^{1,67,68}$.

\section{Other vaccines}

Several vaccines against other agents that cause serious infections in young children are being developed. Vaccines containing live attenuated 
viruses against influenza, rotavirus, respiratory syncytial virus, herpes simplex and parainfluenza are now undergoing advanced testing stages in adults and children. If they prove safe for these age groups, they may then be tested in pregnant women to protect newborns indirectly $y^{2-10,69,70}$.

\section{Vaccines contraindicated during pregnancy}

Vaccines against tuberculosis, measles, mumps, rubella and chickenpox are contraindicated for pregnant women, it being advisable that women in fertile age should avoid pregnancy during the month following vaccination $^{71-79}$.

It is possible that these vaccines are safe during pregnancy; the results from studies conducted in the United States and Canada involving more than 400 pregnant women inadvertently vaccinated against rubella are reassuring because of the absence of cases of congenital rubella syndrome; however, these numbers are not sufficient to ensure that the vaccine will not cause any harm to the fetus ${ }^{74}$.

From March 17, 1995 to March 16,
2000, 362 pregnant women were exposed to the vaccine against chickenpox in the United States; 92 were seronegative and 58 received the vaccine in the first trimester of pregnancy. None of the 56 newborns presented any type of malformation. Due to the small number of cases studied, it was not possible to ensure that the vaccine is exempt of risks for pregnant woman and fetus ${ }^{79}$.

Where non-immune pregnant women are exposed to measles or chickenpox, passive immuno-prophylaxis is recommended ${ }^{1,80}$.

\section{CONCLUSIONS}

In addition to increasing mother protection, the vaccination of pregnant women is an excellent opportunity to confer protection on babies by transferring antibodies passively, whether through the placenta or through breast-feeding. All current evidences are indicative that the vaccines which do not contain live agents and the immunoglobulins being currently recommended for adults are safe and immunogenic for pregnant women and that, even vaccines containing live attenuated viruses, e.g. yellow fever, oral polio and rubella, do not pose risks for the fetus. However, before one can recommend large-scale use, new studies involving a sufficient number of mother-baby pairs are necessary so as to assure the absence of risks for pregnant women and babies. We should mention that, during pregnancy, the vaccination scheme against diphtheria and tetanus should be updated; it is also essential to identify pregnant women in risk groups - who should be vaccinated against influenza and pneumococcus - as well as to check whether the pregnant woman was suitably immunized against rubella and hepatitis B. Children whose mothers are HBsAg carriers should receive vaccine and specific immunoglobulin, preferably within the first 24 hours of life, and those in the puerperium period who are non-immune to hepatitis B or rubella should be vaccinated against these diseases at that time.

It is expected that in the near future the vaccine calendar for pregnant women will be widely expanded, with new vaccines being incorporated.

\section{RESUMO}

BRICKS LF - Vacinação em gestantes: considerações sobre sua importância no Brasil. Rev. Hosp. Clín. Fac. Med. S. Paulo 58 (5):263-274, 2003.

Recém-nascidos e lactentes jovens permanecem vulneráveis a diversas doenças causadas por vírus e bactérias. Em geral, as estratégias de imunização são inefetivas para que a criança produza anticorpos em quantidades suficientes nos primeiros seis meses de vida. Gestantes podem produzir anticorpos IgG que são transportados ati- vamente através da placenta e podem beneficiar tanto a mãe quanto a criança. Entretanto, com poucas exceções, as vacinas não são recomendadas rotineiramente para as gestantes, devido às preocupações relacionadas à segurança desse procedimento. A realização de estudos para avaliar os riscos e benefícios da vacinação em gestantes implica em dificuldades éticas e culturais, tendo baixa aceitação.

Na última década, o desenvolvimento de vacinas, muito seguras e imunogênicas, reativou o debate sobre os riscos e benefícios da vacinação de gestantes, particularmente, quando existe alto risco de a gestante e/ou o feto apresentarem infecção com graves conseqüências.

Neste trabalho, apresentamos uma revisão da literatura sobre a imunização em gestantes, utilizando dados do MEDLINE (1990-2002).

Conclusões: 1) não existem evidências de risco para o feto quando a gestante é imunizada com toxóides, vacinas polissacarídicas, conjugadas ou contendo vírus mortos; 2) provavelmente, a maioria das vacinas contendo vírus atenuados também é segura, 
mas os dados sobre sua segurança ainda são insuficientes; 3) no Brasil, é necessário melhorar a cobertura vacinal de gestantes contra o tétano.

Novas vacinas são candidatas para uso em gestantes, porém, é necessário realizar pesquisas para avaliar sua segurança, eficácia e possíveis indicações, considerando-se dados epidemiológicos regionais.
DESCRITORES: Vacinas. Gravidez. Imunização materna. Doenças infecciosas. Neonatal.

\section{REFERENCES}

1. AMERICAN Academy of Pediatrics - Pikering LK ed. 2000 Red Book. Report of the Committee on Infectious Disease, $25^{\text {th }}$ ed, Chicago, Elk Grove Village, American Academy of Pediatrics, 2000.

2. WATSON JC, PETER G - General immunization practices. In:PLOTKIN SA, ORENSTEIN WA - Vaccines. $3^{\text {th }}$ ed. Philadelphia, Saunders, 1999. p.47-73.

3. ENGLUND JA, GLEZEN WP - Maternal immunization for the prevention of infection in early infancy. Semin Pediatr Infect Dis 1991, 2:225-31.

4. FISHER GW, OTTOLINI MC, MOND JJ - Prospects for vaccines during pregnancy and in the newborn period. Clin Perinatol 1997, 24:231-249.

5. MULHOLLAND K - Maternal immunization for the prevention of bacterial infection in young infants. Vaccine 1998; 16:14641467.

6. ENGLUND J, GLEZEN WP, PIEDRA PA - Maternal immunization against viral disease. Vaccine 1998; 16:1456-1463.

7. GLEZEN WP, ALPERS M - Maternal immunization. Clin Infect Dis 1999; 28:219-224.

8. MUNOZ FM, ENGLUND JA - A step ahead. Infant protection through maternal immunization. Pediatr Clin North Am 2000; 47:449-463.

9. MUNOZ FM, ENGLUND JA - Vaccines in pregnancy. Infect Dis Clin North Am 2001; 15:253-271.

10. GLEZEN PG - Maternal vaccines. Primary Care 2001; 28:791806.

11. HEINONEN OP, SHAPIRO S, MONSON RR et al. - Immunization during pregnancy against poliomyelitis and influenza in relation to childhood malignancy. Int J Epidemiol, 1973, 2:229-235.

12. HARJULEHTO-MERVAALA T, ARO T, HILESMAA VK et al. Oral polio vaccination during pregnancy:no increase in the occurrence of congenital malformations. Am J Epidemiol, 1993, 138 (6):407-414.

13. ELWYN BJ - On behalf of the coordinated data group of bostid researchers. The epidemiology of acute respiratory tract infection in young children:comparison of findings from several developing countries. Rev Infect Dis 1990; 12 (suppl 8):S870-88.

14. MULHOLAND K, MARGOLIS P, MASON K - The WHO Young infants Study Group. Bacterial etiology of serious infections in young infants in developing countries results of a multicenter study. Pediatr Infect Dis J 1999; 18:S17-22.
15. WANG EEL, LAW BJ, STEPHENS D - Pediatric Investigator Collaborative Network on Infections in Canada prospective study of risk factors and outcomes in patients hospitalized with respiratory syncytial viral lower respiratory infection. J Pediatr 1995; 126:212-219.

16. COX MJ, AZEVEDO RS, CANE PA et al. - Seroepidemiological study of respiratory syncytial virus in São Paulo State, Brazil. J Med Virol 1998; 55:234-239.

17. IZURIETA HS, THOMPSON WW, KRAMARZ et al. - Influenza and the rates of hospitalization for respiratory disease among infants and young children. N Engl J Med 2000; 342:232239

18. MALHOTRA A, KRILOV LR - Influenza and respiratory syncytial virus. Pediatr Clin North Am 2000; 47:353-72.

19. GROSS M, BRUNE T, JORCH G et al. - Significance of respiratory syncytial virus (RSV) infection in the $1^{\text {st }}$ year of life. Infection 2000; 28:34-37.

20. GOMEZ M, ALTER S, KUMAR ML et al. - . Neonatal Streptococcal pneumoniae infection:case reports and review of the literature. Pediatr Infect Dis 1999; 18:1014-8.

21. BAKER CJ - Immunization to prevent group B streptococcus diseases. Victories and vexations. J Infect Dis 1990; 161:917921.

22. BRASIL. MINISTÉRIO DA SAÚDE - Disponível no site:www.funasa.gov.br (acesso em 06 de janeiro de 2003)

23. SÃo PAUlo. SECRETARIA DE ESTADO DA SAÚdE, SÃO PAULO - Disponível no site:www. Prefeitura.sp.gov.br (acesso em 20 de novembro de 2002)

24. AMSTEY MS - The potential for maternal immunization to protect against neonatal infections. Semin Perinatol 1991, 15:206.

25. ENGLUND JA, MBAWUIKE IN, HAMMIL H et al. - Maternal immunization with influenza or tetanus toxoid vaccine for passive antibody protection in young infants. J Infect Dis 1993, 168:647-656.

26. WORLD Health Organization - Neonatal Tetanus. Progress towards the global elimination fo neonatal tetanus, 1990-1997. WHO website:www.who.int/vaccines-diseases/ neonatal tetanus. Acesso em 20/05/2002.

27. MARAL I, BAYKAN Z, KAYICIOGLU F - Tetanus immunization in pregnant women:evaluation of maternal tetanus vaccination status and factor affecting rate of vaccination coverage. Public Health 2001, 115:359-364. 
28. BARKER WH, MULLOOLY JP - Pneumonia and influenza deaths during epidemics:implications for prevention. Arch Intern Med 1982; 142:85-89.

29. PUCK JM, GLEZEN WP, FRANK AL et al. - Protection of infants from infection with influenza A virus by transplacentally acquired antibody. J Infect Dis 1980; 142:844-849.

30. REUMAN PD, AYOUB EM, SMALL PA - Effect of passive maternal antibody on influenza illness in children:a prospective study of influenza A in mother-infant pairs. Pediatr Infect Dis J 1987; 6:398 -403

31. YEAGER DP, TOY EC, BAKER B - Influenza vaccination in pregnancy. Am J Perinatol 1999; 16:283-286.

32. SIMONSEN L, FUKADA K, SCHONBERGER LB et al. - The impact of influenza epidemics on hospitalizations. J Infect Dis 2000; 181:831-837.

33. CDC - Prevention and control of influenza:recommendations of the Advisory Committee on Immunization Practices (ACIP). MMWR 2001; 50:1-44

34. AHMED F, SINGLETON JA, FRANKS AL - Influenza vaccination for healthy young adults. N Engl J Med 2001; 345:15431547.

35. SILVERMAN NS, GREIF A - Influenza vaccination during pregnancy. Patient's and physicians's attitudes. J Reprod Med 2001, 46:989-994.

36. SUTTER RW, COCHI SL - Live attenuated poliovirus vaccines. In: PLOTKIN SA, ORENSTEIN WA - Vaccines. $3^{\text {th }}$ ed. Philadelphia, Saunders, 1999. p.364-408.

37. LINDER N, HANDSHER R, FRUMAN O et al. - Effect of maternal immunization with oral poliovirus vaccine on neonatal immunity. Pediatr Infect Dis 1994; 13:959-962.

38. MAHONEY FJ, KANE M - Hepatitis B vaccine. In: PLOTKIN SA, ORENSTEIN WA - Vaccines. $3^{\text {th }}$ ed. Philadelphia, Saunders, 1999. p.158-182.

39. INGARDIA CJ, KELLEY L, LERER T WAX JR - Correlation of maternal and fetal hepatitis B antibody titers following maternal vaccination in pregnancy. Am J Perinatol 1999; 16:129-132.

40. INGARDIA CJ, KELLEY L, LERER T et al. - Hepatitis B vaccination in pregnancy:factors influencing efficacy. Obstet Gynecol 1999; 93:983-986.

41. FEINSTONE SM, GUST ID - Hepatitis A Vaccine. In: PLOTKIN SA, ORENSTEIN WA - Vaccines. $3^{\text {th }}$ ed. Philadelphia, Saunders, 1999. p.650-671.

42. MONATH TP - Yellow fever. In: PLOTKIN SA, ORENSTEIN WA - Vaccines. $3^{\text {th }}$ ed. Philadelphia, Saunders, 1999. p.815879

43. ROBERT E, VIAL T, SCHAEFER C et al. - Exposure to yellow fever vaccine in early pregnancy. Vaccine 1999; 17:283285

44. AMARAL E, PAPAIORDANOU P, SATO HK et al. - Estudo de coorte de gestantes vacinadas contra a febre amarela na região de Campinas em fevereiro e março de 2000. Apresentado no 42th ICAAC, Chicago, 2000.
45. SAHID NS, STEINHOFF MC, HOQUE SS et al. - Serum, breast milk, and infant antibody after maternal immunization with a pneumococcal polysaccharide vaccine during pregnancy. Lancet $1995 ; 346: 1252-1257$.

46. O’DEMPSEY TDJ, McARDLE T, CEESAY SJ et al. Immunization with a pneumococcal polysaccharide vaccine during pregnancy. Vaccine 1996;14:963-970.

47. GLEZEN WP - Pneumococcal polysaccharide vaccine in pregnancy. Pediatrics 1999 104; 1417-8.

48. BEKEN ET, DALY KA, LINDGREEN BR et al. - MELAND MH, GIEBINK GS. Low cord blood pneumococcal antibody concentrations predict more episodes of otitis media. Arch Otolaryngol Head Neck Surg 2001; 127:517-22.

49. BLACK S, SHINEFIELD H, FINEMAN B et al. — Efficacy safety and immunogenicity of hepatavalent pneumococcal vaccine in children. Pediatr Infect Dis J 2000; 19:187-195.

50. OBARO SK - Prospects for pneumococcal vaccination in Africa. Acta Tropica 2000; 75:141-143.

51. MUNOZ FM, ENGLUND JA, CHEESMAN CC et al. - - Maternal immunization with pneumococcal polysaccharide vaccine in the third trimester of gestation. Vaccine 2002; 20:826-837.

52. LEPOW ML, PERKINS BA, HUGHES PA et al. - Meningococcal vaccines. In: PLOTKIN SA, ORENSTEIN WA - Vaccines. $3^{\text {th }}$ ed. Philadelphia, Saunders, 1999. p. 711-27.

53. LETSON GW, LITTLE JR, OTTMAN J et al. - Meningococcal vaccine in pregnancy:an assessment of infant risk. Pediatr Infect Dis J 1998; 17:261-3.

54. PREVENTION and control of meningococcal disease. Recommendations of the Advisory Committee on Immunization Practices (ACIP). MMWR 2000; 49 (RR-07):1-10.

55. ESKOLA J, KAYHTY H - Early immunization with conjugate vaccines. Vaccine 1998; 16:1433-1438.

56. AMSTEY MS, INSEL R, MUNOZ J - Fetal-neonatal passive immunization against Haemophilus influenzae type b. Am J Obstet Gynecol 1985;155:607.

57. GLEZEN WP, ENGLUND JA, SIBER GR - Maternal immunization with the capsular polysaccharide vaccine for Haemophilus influenzae type b. J Infect Dis 1992; 165(Suppl 1):134-6.

58. ENGLUND JA, GLEZEN WP, TURNER C et al. - Transplacental antibody transfer following maternal immunization with polysaccharide and conjugate Haemophilus influenzae type b vaccines. J Infect Dis 1995; 171:99-105.

59. ENGLUND JA, GLEZEN WP, THOMPSON C et al. - Haemophilus influenzae type $\mathrm{b}$ especific antibody in infants after maternal immunization. Pediatr Infect Dis J 1997; 16:1122-1130.

60. MULHOLLAND K, SUARA R, SIBERG et al. - Maternal immunization with Haemophilus influenzae type b polysaccharide-tetanus protein conjugate vaccines in The Gambia. JAMA 1996; 275:1182-1188.

61. MUNOZ FM, GLEZEN WP, NAHAM M et al. - Effect of third trimester maternal immunization with Haemophilus influenzae type $\mathrm{b}$ conjugate vaccine in the infants immune response to primary immunization. Clin Infect Dis 1999; 29:1077. 
Vaccines in pregnancy: a review of their importance in Brazil Bricks LF

62. OKOKO BJ WESUMPERUMA LH, HART AC - Materno-foetal transfer of $H$. influenzae and pneumococcal antibodies is influenced by prematurity and low birth weight:implications for conjugate vaccine trials. Vaccine 2002; 647-650.

63. BAKER CJ, RENCH M, EDWARDS M et al. - Immunization of pregnant women with polysaccharide vaccine of group B streptococcus. N Engl J Med 1988; 319:1180-1185.

64. KASPER DL, PAOLETTI LC, WESSELS ME et al. - Immune response to type III group B streptococcal polysaccharide tetanus toxoid conjugate vaccine. J Clin Invest 1996; 98:23082314.

65. BAKER CJ, PAOLETTI LC, WESSELS MR et al. - Safety and immunogenicity of capsular polysaccharide-tetanus toxoid conjugate vaccines for group B streptococcal types $1 \mathrm{a}$ and $1 \mathrm{~b}$. J Infect Dis 1999; 179:142-150.

66. LIN FY, PHILIPS JB, AZIMI PH et al. - Level of maternal antibody required to protect neonates against early-onset disease casued by group B streptococcus type I1:a multicenter seroepidemiology study. J Infect Dis 2001; 184:1022-8.

67. KEITEL WA, EDWARDS KM - Pertussis in adolescents and adults. Time to reimmunizae? Semin Respir Infect 1995; 10:51-57.

68. KENDRIK P, TOMPSON M, ELDERING G - Immune response o f mother and babies to infections of pertussis vaccine during during pregnancy. Am J Child Dis 1945; 70:25-28.

69. BRICKS LF - Prevention of respiratory syncytyal virus infections. Rev Hosp Clin Fac Med S. Paulo 2001; 56:79-90.

70. SRANBERRY LR, CUNNINGHEM AL, MINDEL A et al. Prospects for control of herpes simplex virus diseases through immunization. Clin Infect Dis 2000; 30:549-566.
REV. HOSP. CLÍN. FAC. MED. S. PAULO 58(5):263-274, 2003

71. KAMAT M, PYAT S, PILDES RS - Measles antibody titers in early infancy. Arch Pediatr Adolesc Med 1994; 148:694-8.

72. PLOTKIN - Rubella vaccine. In: PLOTKIN SA, ORENSTEIN WA - Vaccines. $3^{\text {th }}$ ed. Philadelphia, Saunders, 1999. p.409439.

73. CDC - Revised ACIP recommendation for avoiding pregnancy after receiving a rubella containing vaccine. MMWR Morb Mortal Wkly Rep 2000; 49:1117.

74. JOSEFSON D - Rubbella vaccine may be safe in early pregnancy. BMJ 2001; 322:695.

75. GERSHON AA, TAKAHASHI M, WHITE CJ - Varicella vaccine. In: PLOTKIN SA, ORENSTEIN WA - Vaccines. $3^{\text {th }}$ ed Philadelphia, Saunders, 1999. p.475-507.

76. WALD ER - Transmission of varicella-vaccine virus:what is the risk? J Pediatr 1997; 133(2):310-1.

77. WALD ER - Transmission of varicella-vaccine virus:what is the risk? J Pediatr 1997; 131(1 Pt 1):151-4.

78. RAJAN P, RIVERS JK - Varicella zoster virus. Recent advances in management. Can Fam Physician 2001; 47; 2299-2304.

79. SHIELDS KE, GALIL K, SEWARD J et al. - Varicella vaccine exposure during pregnancy:data from the first 5 years of the pregnancy registry. Am Coll Obst Gynecol 2001; 98:14-19.

80. NOWAK-WEGRZYN A, LEDERMAN HM - Supply, use, and abuse of intravenous immunoglobulin. Curr Opin Pediatr 1999; 11:533-539. 